\title{
First Report of Tenosynovitis Caused by Mycobacterium virginiense in Korea
}

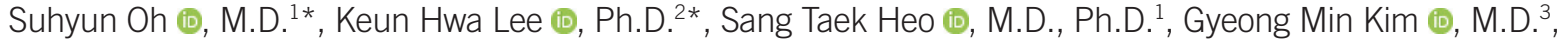 \\ Young Ree Kim (i), M.D., Ph.D. ${ }^{4}$, and Jeong Rae Yoo $\mathbb{0}$, M.D. ${ }^{1}$ \\ Departments of ${ }^{1}$ Internal Medicine and ${ }^{2}$ Microbiology, Jeju National University College of Medicine and Graduate School of Medicine, Jeju, Korea; \\ ${ }^{3}$ Department of Orthopedic Surgery, Jeju National University Hospital, Jeju, Korea; ${ }^{4}$ Department of Laboratory Medicine, Jeju National University College of \\ Medicine and Graduate School of Medicine, Jeju, Korea
}

\section{Dear Editor,}

Mycobacterium terrae complex (MTC) are slow-growing nontuberculous mycobacteria (NTM) that cause tenosynovitis, septic arthritis, and osteomyelitis of the extremities [1]. Eleven new species of MTC have been described since 2006 [2]. Mycobacterium virginiense, a member of the MTC, was first described in 2016, and isolates from patients with tenosynovitis and osteomyelitis are acid-fast, slow-growing, and nonpigmented on Middle brook 7H10 agar [2]. The first case of $M$. virginiense isolated from a human pulmonary specimen was reported in 2019 [3]. We report the first case of tenosynovitis caused by $M$. virginiense in Korea. This retrospective study was approved by the Institutional Review Board of Jeju National University Hospital, Jeju, Korea (No. 2019-07-018) that waived informed consent.

A previously healthy 68-year-old woman was admitted to Jeju National University Hospital with painful swelling of the third finger of her left hand, which had been present for one month; her hand was treated with acupuncture two months before admission. She had a leukocyte count of 5.70 (reference range: 4.5$11.0) \times 10^{9} / \mathrm{L}$, an erythrocyte sedimentation rate of 41 (reference range: $0-20) \mathrm{mm} / \mathrm{hr}$, and $\mathrm{C}$ reactive protein levels of 2.10 (reference range: $0.76-28.5) \mathrm{nmol} / \mathrm{L}$. Magnetic resonance imaging of her left hand revealed an effusion, synovial proliferation of the flexor tendon sheath, and subcutaneous fat edema of the third finger (Fig. 1). She was treated empirically with cefazolin and clindamycin for three weeks following which she underwent surgical debridement. Tenosynovitis and severe inflammatory changes of the soft tissue surrounding the flexor tendon were observed during surgery. Bacterial culture, acid-fast bacilli (AFB) stain, and tuberculosis (TB)-PCR were negative in the tissue specimen of the inflammatory soft tissue surrounding the tendon. On day 22, an AFB culture performed at the Korean Institute of Tuberculosis revealed an unidentified NTM. Cefazolin and clindamycin were discontinued, and oral clarithromycin (500 mg twice a day) and intravenous amikacin (10 mg/kg/day) and cefoxitin (12 g/day) were started, based on a presumptive diagnosis of rapid-growing NTM infection. Two weeks later, the regimen was changed to oral clarithromycin and ciprofloxacin (500 mg twice a day). The patient improved clinically and was discharged on hospital day 40.

Molecular methods, including rpoB gene PCR, were used for definitive species identification, and slow-growing $M$. virginiense was confirmed with an accuracy of 99\% (341/343 bp) using the basic local alignment search tool algorithm (Fig. 2) [4]. The rpoB
Received: July 21, 2019

Revision received: August 19, 2019

Accepted: September 23, 2019

Corresponding author: Jeong Rae Yoo, M.D.

Department of Internal Medicine, Jeju National University College of Medicine and Graduate School of Medicine, 15 Aran 13-gil, Jeju 63241, Korea

Tel: +82-64-717-2833, Fax: +82-64-717-1131, E-mail: mdyoojr@gmail.com

\section{(c) (1) (2)}

\section{(C) Korean Society for Laboratory Medicine}

This is an Open Access article distributed under the terms of the Creative Commons Attribution Non-Commercial License (http://creativecommons.org/licenses/by-nc/4.0) which permits unrestricted non-commercial use, distribution, and reproduction in any medium, provided the original work is properly cited.

*These authors contributed equally to this work. 


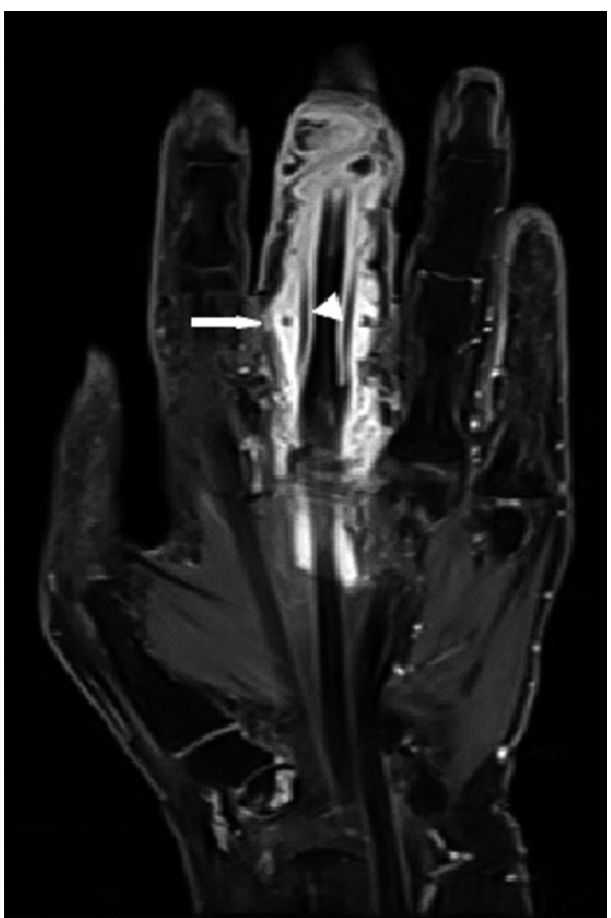

Fig. 1. Coronal T1-weighted, fat-suppressed, turbo spin-echo image showing effusion (arrowhead) and synovial proliferation on the flexor tendon sheath of the third finger of the left hand (white arrow). gene sequences were aligned using the multiple-alignment algorithm in the MegAlign program (Windows version 3.12e; DNASTAR, Madison, WI, USA) and the ClustalX program (Toby Gibsonm, Des Higgins, Julie Thompson, EMBL, Heidelberg, Germany). Phylogenetic analyses were conducted in MEGA6 (https: //www.megasoftware.net) based on the aligned sequences, and phylogenetic trees were constructed using the maximum likelihood method [5].

Antimicrobial susceptibility was determined at the Korean Institute of Tuberculosis using the CLSI agar microdilution method [5]. The isolate was susceptible to clarithromycin (minimal inhibitory concentration $[\mathrm{MIC}] \leq 0.5 \mathrm{mg} / \mathrm{L}$ ), but resistant to amikacin $(\mathrm{MIC}>128 \mathrm{mg} / \mathrm{L})$, cefoxitin $(\mathrm{MIC}=8 \mathrm{mg} / \mathrm{L})$, ciprofloxacin $(\mathrm{MIC}>$ $16 \mathrm{mg} / \mathrm{L})$, doxycycline $(\mathrm{MIC}=8 \mathrm{mg} / \mathrm{mL})$, ethambutol $(\mathrm{MIC}=4$ $\mathrm{mg} / \mathrm{L})$, imipenem (MIC>64 mg/L), linezolid (MIC=8 mg/L), moxifloxacin ( $\mathrm{MIC}>16 \mathrm{mg} / \mathrm{L})$, rifampin ( $\mathrm{MIC}=4 \mathrm{mg} / \mathrm{L})$, trimethoprim/ sulfamethoxazole (TMP/SMX; MIC =16/304 mg/L), and tobramycin ( $\mathrm{MIC}>32 \mathrm{mg} / \mathrm{L}$ ). The patient was treated with clarithromycin for three months, and the infection healed.

There is no standard treatment for $M$. virginiense infection. Some MTC isolates are susceptible to ethionamide, azithromycin, amikacin, ciprofloxacin, streptomycin, linezolid, cycloserine,

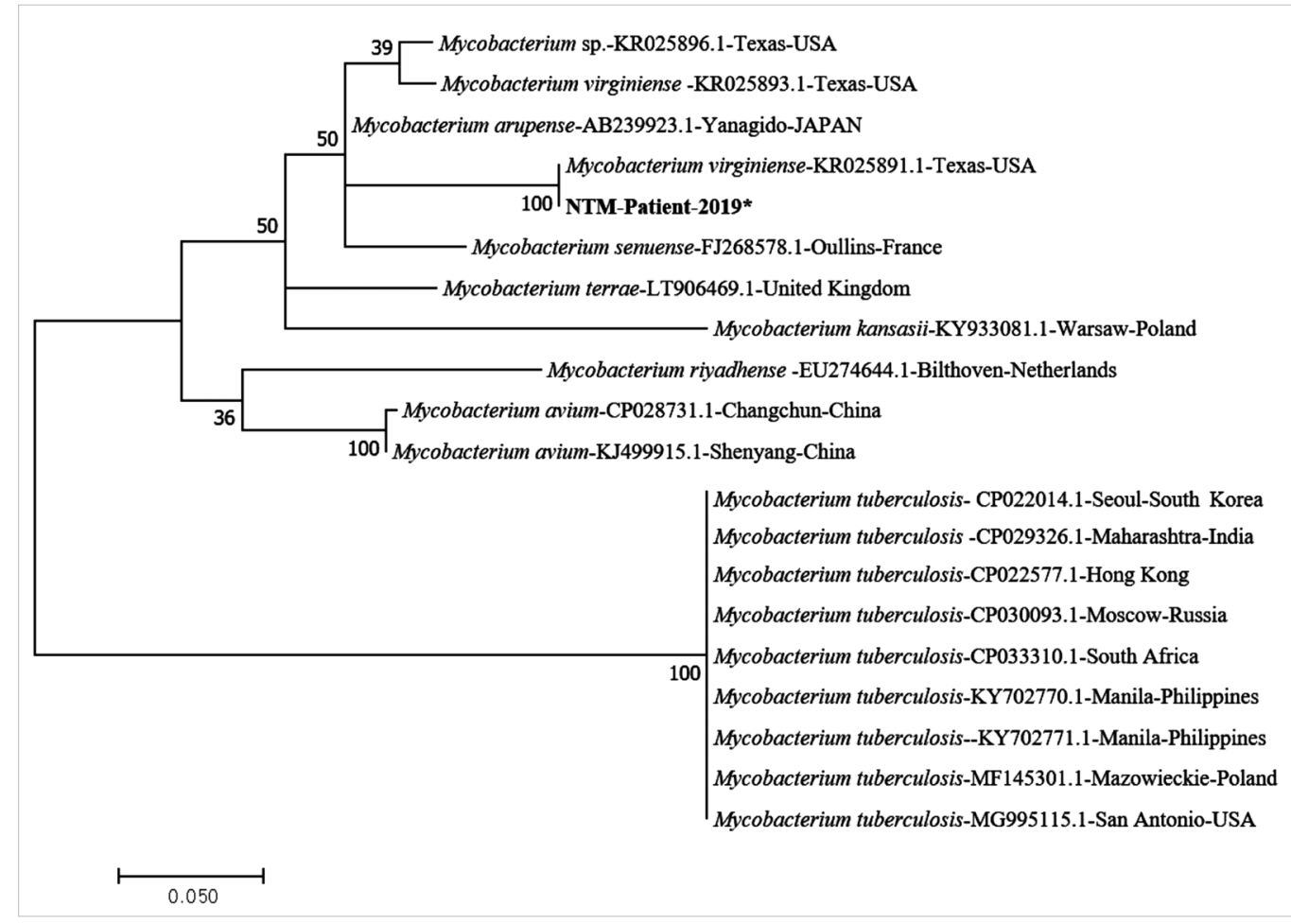

Fig. 2. Phylogenetic tree constructed based on the rpoB gene of Mycobacterium virginiense.

*The rpoB gene sequence of $M$. virginiense from the patient's tissue specimen is shown in bold (NTM patient-2019).

Abbreviation: NTM, nontuberculous mycobacteria. 
TMP/SMX, and some aminoglycosides [1, 6]. The M. virginiense isolate described in 2016 was susceptible to clarithromycin, ethambutol, rifabutin, and TMP/SMX, but was resistant to amikacin, rifampin, quinolone, doxycycline, and linezolid [2]. The pulmonary isolate from Korea was resistant to all antibiotics except clarithromycin [3]. Because of the limited number of reports, it is not possible to determine whether Korean $M$. virginiense strains have higher drug resistance than strains from other countries. However, M. virginiense infections in Korea should be regarded as possibly multidrug resistant.

According to the American Thoracic Society guidelines, prolonged combination antibiotic therapy with surgical debridement is important, and probably essential, for recovery from NTM infection [7]. In our case, the choice of antimicrobial therapy was limited as the strain was multidrug-resistant; however, the patient improved clinically following surgery. In addition, as NTMcaused skin and soft tissue infections have been reported following intramuscular injection, cosmetic surgery, and acupuncture, physicians should take this medical history into consideration [8].

Nonspecific clinical manifestations, lack of knowledge, and inadequate laboratory services often delay diagnosis of NTM infection. Further testing of the unidentified NTM and the introduction of new methods to elucidate various NTM subspecies are necessary to improve the diagnosis and treatment of $M$. virginiense and other NTM infections. In addition, we recommend performing a pathological examination in cases of prolonged infectious disease, because the causative microorganism may not have been identified. Physicians need to be alert to the possibility of $M$. virginiense infection because it is not identified by the tests used at the Korean Institute of Tuberculosis. In addition, in cases of NTM infection, it is important to identify the strain correctly and to determine antimicrobial susceptibility.

\section{Author Contributions}

$\mathrm{KHL}$ and YRK performed experiments; SHO and JRY wrote the manuscript; STH and GMK analysed data.

\section{Conflicts of Interest}

No potential conflicts of interest relevant to this paper were reported.

\section{Research Funding}

None declared.

\section{ORCID}

Suhyun Oh

Keun Hwa Lee

https://orcid.org/0000-0002-5780-2835

Sang Taek Heo https://orcid.org/0000-0002-2259-2751

Gyeong Min Kim https://orcid.org/0000-0001-8947-5069

Young Ree Kim https://orcid.org/0000-0002-7535-5979

Jeong Rae Yoo https://orcid.org/0000-0003-2454-8815 https://orcid.org/0000-0002-5488-7925

\section{REFERENCES}

1. Lembo G, Goldstein EJ, Troum O, Mandelbaum B. Successful treatment of Mycobacterium terrae complex infection of the knee. J Clin Rheumatol 2012;18:359-62.

2. Vasireddy R, Vasireddy S, Brown-Elliott BA, Wengenack NL, Eke UA, Benwill JL, et al. Mycobacterium arupense, Mycobacterium heraklionense, and a newly proposed species, "Mycobacterium virginiense" sp. nov., but not Mycobacterium nonchromogenicum, as species of the Mycobacterium terrae complex causing tenosynovitis and osteomyelitis. J Clin Microbiol 2016;54:1340-51.

3. Jung J, Yoo IY, Jhun BW, Koh WJ, Lee NY, Huh HJ. First isolation of Mycobacterium virginiense from a human pulmonary specimen. Ann Lab Med 2019;39:596-8.

4. Tamura K, Stecher G, Peterson D, Filipski A, Kumar S. MEGA6: molecular evolutionary genetics analysis version 6.0. Mol Biol Evol 2013;30: 2725-9.

5. CLSI. Susceptibility testing of mycobacteria, nocardiae, and other aerobic actinomycetes. 2nd ed. CLSI M24-A2. Wayne, PA: Clinical and Laboratory Standards Institute. 2011.

6. Smith DS, Lindholm-Levy P, Huitt GA, Heifets LB, Cook JL. Mycobacterium terrae: case reports, literature review, and in vitro antibiotic susceptibility testing. Clin Infect Dis 2000;30:444-53.

7. Griffith DE, Aksamit T, Brown-Elliott BA, Catanzaro A, Daley C, Gordin F, et al. An official ATS/IDSA statement: diagnosis, treatment, and prevention of nontuberculous mycobacterial diseases. Am J Respir Crit Care Med 2007;175:367-416.

8. Yu JR, Heo ST, Lee KH, Kim J, Sung JK, Kim YR, et al. Skin and soft tissue infection due to rapidly growing mycobacteria: case series and literature review. Infect Chemother 2013;45:85-93. 